\title{
GÊNEROS TEXTUAIS, MULTILETRAMENTO E PRODUÇÃO DE JORNAL DIGITAL
}

\author{
GÉNERO TEXTUAL, MULTILITERACIÓN Y PRODUCCIÓN DIGITAL DE \\ PERIÓDICOS
}

\author{
TEXTUAL GENDER, MULTILITERACY AND DIGITAL NEWSPAPER PRODUCTION
}

\author{
Madalena Regina Garcia PARREÃO ${ }^{1}$ \\ Ângela Rita Christofolo de MELLO ${ }^{2}$
}

RESUMO: Este artigo apresenta resultados de uma pesquisa ação, de abordagem qualitativa, realizada com o objetivo de incentivar o trabalho com diferentes gêneros textuais da esfera jornalística em práticas educacionais de incentivo à leitura e à produção de textos a partir da criticidade dos estudantes matriculados no $9^{\circ}$ ano do ensino fundamental, acerca da realidade social. $\mathrm{O}$ resultado deste trabalho permite afirmar que os conteúdos quando trabalhados de forma contextualizada e articulada aos fatos atuais, darão vida e sentido aos temas estudados nas aulas de Língua Portuguesa. Esses aspectos são recomendados porque poderão mudar os resultados obtidos na aprendizagem.

PALAVRAS-CHAVE: Língua portuguesa. Projeto de letramento. Aprendizagem.

RESUMEN: Este artículo presenta resultados de una investigación acción, con enfoque cualitativo, realizada con el objetivo de incentivar el trabajo con diferentes géneros textuales del ámbito periodístico en prácticas educativas para incentivar la lectura y la producción de textos a partir de la criticidad de los estudiantes matriculados en el $9^{\circ}$ grado de primaria, sobre la realidad social. El resultado de este trabajo nos permite afirmar que los contenidos, trabajados de forma contextualizada y articulados a la actualidad, darán vida y significado a los contenido estudiados en las clases de Lengua Portuguesa. Se recomiendan estos aspectos porque pueden cambiar los resultados obtenidos en el aprendizaje.

PALABRAS CLAVE: Lengua portuguesa. Proyecto de literatura. Aprendiendo.

ABSTRACT: This article presents results of an action research, with a qualitative approach, carried out with the objective of encouraging the work with different textual genres of the journalistic sphere in educational practices to encourage reading and the production of texts based on the criticality of students enrolled in the 9th grade elementary school, about the

${ }^{1}$ Universidade do Estado de Mato Grosso (UNEMAT), Sinop - MT - Brasil. Mestrado pelo Programa de PósGraduação em Letras, Mestrado Profissional em Letras (PROFLETRAS). ORCID: https://orcid.org/0000-00017623-9315. E-mail: madajusc@gmail.com

${ }^{2}$ Universidade do Estado de Mato Grosso (UNEMAT), Juara - MT - Brasil. Professora do curso de pedagogia, do Programa de Pós-Graduação Stricto Sensu em Educação (PPGEDU), e do Programa de Pós-Graduação em Letras, Mestrado Profissional em Letras (PROFLETRAS). Líder do Grupo de Pesquisa de Formação Docente, Gestão e Prática Educacional (GEFOPE/CNPq). Doutorado em Educação (UNIMEP). ORCID: https://orcid.org/0000-0002-9732-6175. E-mail: angela.mello@unemat.br

RPGE- Revista on line de Política e Gestão Educacional, Araraquara, v. 25, n. 2, p. 1346-1363, maio/ago. 2021. e-ISSN: 1519-9029 DOI: https://doi.org/10.22633/rpge.v25i2.14793 
social reality. The result of this work allows us to affirm that the contents, when worked in a contextualized way and articulated to current facts, will give life and meaning to the themes studied in Portuguese Language classes. These aspects are recommended because they can change the results obtained in learning.

KEYWORDS: Portuguese language. Literacy project. Learning.

\section{Introdução}

O manuscrito publiciza resultados de uma pesquisa-ação de abordagem qualitativa, realizada no âmbito do Programa de Pós-Graduação em Letras (Profletras), ofertado na Universidade do Estado de Mato Grosso (UNEMAT), Campus de Sinop, que teve como objeto de estudo, o desdobramento de um projeto de letramento, planejado a partir de quatro Sequências Didáticas (SD), realizado em uma escola estadual de Mato Grosso, com uma turma de $9^{\circ}$ ano. A pesquisa foi aprovada pelo Comitê de Ética em Pesquisa (CEP), da Universidade do Estado de Mato Grosso, conforme CAAE: 81913717.9.0000.5166, parecer n. 2.474.720 (2018).

O objetivo da pesquisa foi publicizar possibilidades de planejamentos e intervenções docentes com gêneros textuais da esfera jornalística em práticas educacionais de incentivo à leitura e à produção de textos a partir da criticidade dos estudantes acerca da realidade social. Desta feita, o projeto de letramento desenvolvido nas aulas de língua portuguesa, incluiu atividades com foco na interação entre os envolvidos, por meio da utilização dos recursos digitais que contribuíssem com a aprendizagem da língua, a fim de oportunizar o desenvolvimento cognitivo e o protagonismo juvenil dos estudantes.

Como destacam os Parâmetros Curriculares Nacionais (PCNs) (BRASIL, 1998), o fracasso escolar, tanto no ensino fundamental, quanto médio, reside no fato da não apropriação da leitura, interpretação e produção escrita. Os resultados mostrados nas avaliações externas realizadas nas escolas públicas, nos últimos anos, tais como o Sistema Nacional de Avaliação da Educação Básica (SAEB) e o Programa Internacional de Avaliação (PISA), confirmaram esse fracasso e advertiram que há lacunas no ensino de língua portuguesa em todo o Brasil.

Nesse contexto, surgiu a intenção de desenvolver um projeto de letramento que utilizasse os gêneros textuais da esfera jornalística, tomando por base os pressupostos teóricos de que "frequentemente o jornal tem sido um grande aliado na reformulação de alguns valores 
didáticos da atualidade" (CAVALCANTI, 1999, p. 42), e contribui para fortalecer a educação em uma perspectiva de formação integral dos estudantes.

A utilização do jornal enquanto recurso didático propiciará ao estudante uma maior interação com o mundo que o cerca ao despertar o interesse em ler e escrever textos da realidade social. Destaca-se ainda, que a mídia exerce uma forte influência na vida das pessoas e da sociedade em geral, como afirma Cavalcanti (1999, p. 31), "muitos até dizem que a imprensa representa o quarto poder e, na realidade, isso tem fundamento, pois ela orienta e redimensiona o entendimento da realidade. Ela está por toda a parte e o que diz parece absolutamente verdade". Por isso, o jornal torna-se um suporte de gêneros textuais que muito pode contribuir com o trabalho docente, mesmo porque "[...] é um meio de comunicação social que informa e opina, possibilitando aos leitores o contato com um conjunto de informações acerca dos acontecimentos mundiais [...], um grande formador de significado." (LOZZA, 2009, p. 33).

Desta feita, compreende-se que o desenvolvimento da competência linguísticodiscursiva, amplia o senso crítico ao sensibilizar o estudante com relação aos acontecimentos, bem como permite a realização de diferentes leituras. A produção de gêneros textuais jornalísticos possibilita, também, o trabalho no ambiente digital a partir do uso das tecnologias para a produção dos textos, formatação e manuseio de imagens. Esses recursos tecnológicos quando utilizados adequadamente, poderão favorecer a leitura, a criatividade e despertar nos estudantes o interesse pela busca de informação. Por sua vez, as informações quando problematizadas e articuladas aos contextos políticos, socioculturais e econômicos reais, favorecem o domínio da oralidade e o desenvolvimento de posicionamentos críticos e reflexivos dos estudantes.

Destaca-se ainda que, ao idealizar um trabalho utilizando-se gêneros textuais jornalísticos como base para as propostas de intervenções pedagógicas, refletiu-se como esses gêneros poderiam influenciar as concepções de leitura, compreensão e produção de textos nas aulas de Língua Portuguesa, por meio de um trabalho articulado aos acontecimentos que cerceiam as diferentes práticas sociais na dinâmica da vida do estudante.

Diante do contexto observado, a escolha do jornal justificou-se por tratar-se de um suporte de textos que comporta uma grande diversidade de gêneros, e poderia proporcionar leitura de mundo e visão ampla de fatos e acontecimentos presentes na esfera social, ou seja, uma leitura que vai além das palavras, pois o jornal traz, ainda, imagens, cores e figuras que permitem leituras dinâmicas e não lineares. Vale ressaltar que, o jornal é um veículo de comunicação de massa, sua abrangência extrapola o interior da sala de aula e sua utilização 
pode trazer subsídios para ampliar o aprendizado dos estudantes a partir de novas experiências de leitura.

Pode-se observar que o jornal como instrumento para o trabalho pedagógico, possibilita ao estudante o acesso a diferentes gêneros textuais, condição que corrobora para a ampliação dos conhecimentos sociais e culturais. Com isso, aumenta o poder de reflexão e, consequentemente, a capacidade intelectual e possibilita, ainda, o acesso às novas tecnologias digitais ao oportunizar o manuseio de imagens, áudios e vídeos necessários para a construção dos textos, o que poderá incentivar os estudantes à criação e produção de materiais. Assim, o trabalho com os gêneros presentes no jornal corrobora que o letramento em sala de aula seja dinâmico e interativo.

Esta condição possibilita o acesso às múltiplas linguagens e formas de expressão, bem como a utilização de tecnologias digitais que contribuam significativamente para a formação cidadã do estudante e seu desempenho como leitor e/ou produtor de textos. Como Lozza (2009, p. 35) afirma, “o jornal é uma mercadoria especial, pois ao mesmo tempo em que é noticioso, também dissemina ideias, valores, interpretações por meio das notícias que o compõem".

\section{Abordagem metodológica de um estudo pautado nos princípios da pesquisa-ação}

Com vistas a alcançar os objetivos propostos, realizou-se uma pesquisa ação (THIOLLENT, 2008, p. 14) que, fundamentada na abordagem qualitativa em que a análise das informações e episódios registrados, interpretou "como os atores sociais envolvidos nesse processo o percebem [...].” (BORTONI-RICARDO, 2008, p. 32). Nesse sentido, registrou-se que no decorrer do projeto de pesquisa-ação realizado, os envolvidos tiveram a oportunidade de refletir, discutir e opinar sobre as atividades planejadas e trabalhadas coletiva e individualmente. Também sugeriram, sempre que necessário, o redimensionamento das ações planejadas.

Para desenvolver as etapas necessárias, adotou-se o Projeto de Letramento (PL), fundamentado em Kleiman (1999). O PL foi organizado em quatro Sequências Didáticas (SD), pautadas nos pressupostos de Dolz e Schenewly (2004), uma vez que o jornal produzido pelos estudantes se compôs de diferentes gêneros textuais desta esfera de produção.

O diário de campo foi um instrumento adotado que possibilitou registrar as observações e demais ponderações em relação às atividades pedagógicas trabalhadas. Segundo os pressupostos de Zabalza (2004), o diário é um importante instrumento para os 
registros de informações observadas no decorrer de um processo de intervenção. Ao sensibilizar o educador/pesquisador para a prática do registro, incentiva-o a observar as ações pedagógicas trabalhadas no projeto, de modo que as experiências vividas em sala de aula, os resultados obtidos com a realização de cada $\mathrm{SD}$, os sucessos e insucessos ocorridos no desdobramento de todas as etapas da pesquisa-ação, fossem detalhadamente descritas.

A intervenção docente ocorreu num período de aproximadamente seis meses. Foram disponibilizadas quatro aulas de língua portuguesa, duas vezes por semana, que somaram trinta e três encontros e totalizaram sessenta e seis horas-aula, acrescidas dos encontros realizados em contra turno, que aconteceram de acordo com as necessidades de correções e refazeres dos gêneros textuais trabalhados, bem como as atividades realizadas no laboratório de informática e on-line, que aconteceram a partir do grupo de WhatsApp criado para interações, discussões de atividades, sugestões de temas, além dos e-mails trocados no momento de edição e organização dos textos para a publicação do jornal digital lançado como produto final do projeto.

\section{Projeto de letramento: uma proposição planejada a partir de sequências didáticas}

O projeto envolveu vinte e nove estudantes na faixa entre 13 e 14 anos, matriculados no $9^{\circ}$ ano do período matutino, de uma escola da rede pública estadual, oriundos das localidades próximas à escola e demais bairros do município.

O desenvolvimento da pesquisa-ação teve como principal objetivo realizar intervenções desdobradas a partir da utilização dos gêneros da esfera jornalística, com a finalidade de desenvolver as habilidades de leitura, interpretação e produção textual, por meio da exploração dos gêneros diversificados que compõem o jornal.

A discussão das análises vinculou-se ao campo da linguística aplicada e teve como fundamentação teórica os estudos de Kleiman (1999; 2005), Rojo (2009; 2012), Marcuschi (2005; 2008), Bakhtin (2003), Bazerman (2006), bem como outros autores que dialogam entre si e deram sustentação à pesquisa.

O trabalho em sala de aula teve como base teórica os conceitos do planejamento pautados nos pressupostos da SD de Dolz e Schneuwly (2004). Essa proposição didática possibilitou aos estudantes conhecerem gêneros discursivos que não dominavam ou dominavam de forma insuficiente e que dificilmente teriam acesso espontaneamente na sala de aula. Os desdobramentos das SD permitiram-lhes o reconhecimento de novas práticas de 
linguagem, ajudando-os a identificar a função social dos diversos gêneros textuais, presentes nas diferentes esferas sociais, que potencializam as capacidades de ler e escrever.

Tomando como base a estrutura da SD, na apresentação do projeto, o professor descreve de maneira detalhada a atividade que os estudantes desenvolverão, seja na modalidade oral, ou escrita. Assim, a conversa sobre o gênero textual a ser produzido, apresentará a situação de comunicação e o contexto de produção em que estarão envolvidos, preparando-os para a primeira produção do gênero textual a ser trabalhado. Esse é um momento importante em que o professor deve adotar uma metodologia adequada à turma, assegurando-se de que suas escolhas linguísticas poderão definir o resultado do trabalho. Como destacam Dolz e Schneuwly (2004, p. 97):

O trabalho escolar realizado, evidentemente, se desdobra a partir dos gêneros que os estudantes não dominam ainda, ou o fazem de maneira insuficiente; sobre aqueles dificilmente acessíveis, espontaneamente, pela maioria dos alunos; e sobre gêneros públicos e não privados [...]. Desse modo, as sequências didáticas servem, portanto, para dar acesso aos alunos a práticas de linguagem novas ou dificilmente domináveis.

Segundo os autores, uma atividade escolar satisfatória será considerada aquela que se baseia nos estudos dos gêneros textuais. Como afirma Bakhtin (2003, p. 301), “[...] para falar, utilizamos sempre os gêneros do discurso, em outras palavras, todos os nossos enunciados dispõem de uma forma padrão e relativamente estável de estruturação de um todo".

Portanto, é necessário considerar que as atividades propostas em sala de aula a partir de gêneros, contribuem para o desenvolvimento da competência textual dos estudantes, pois propiciam a eles a oportunidade de ampliar seus conhecimentos não só por meio da observação das características presentes em cada gênero, como também a partir da interpretação dos fatos, da divulgação de opiniões, bem como da reflexão sobre temas atuais. Com isso, poderão desenvolver suas habilidades de leitura e escrita, como protagonistas de seu trabalho de produção oral ou escrita.

A partir dessas considerações, com o suporte do projeto de letramento, planejou-se quatro SD que foram trabalhadas com o objetivo de propiciar aos estudantes condições de elaboração de diferentes gêneros textuais que compõem a esfera jornalística, e, com isso, produzir material suficiente para a organização do primeiro jornal digital da escola. ${ }^{3}$

3 Os planejamentos integrais das $4 \mathrm{SD}$, bem como os seus desdobramentos. Disponível em: https://drive.google.com/file/d/1ApbGx5cwISGILJEIRy4lwFYx2_aK1wrP/view. Acesso em: 16 fev 2021. 


\section{Para começo de conversa: apresentando a situação}

Inicialmente, realizou-se uma conversa interativa com a turma sobre o jornal impresso e as finalidades da realização do projeto de intervenção pedagógica com aquela turma de estudantes. Para as ações iniciais que englobaram seis aulas, tomaram-se por base pressupostos teóricos de Freire (1996) que valorizam o diálogo como forma de interação entre estudantes e professores de modo que o educando se perceba sujeito na construção do seu conhecimento, enquanto o professor privilegia a autonomia desses com vistas a conduzir a aprendizagem como um processo social.

Para o primeiro encontro, organizou-se uma roda de conversa permitindo aos estudantes sanarem suas dúvidas sobre o projeto, e abrindo espaço para a professora conhecer melhor a realidade da turma. Observou-se que um expressivo número de estudantes possuía poucos hábitos de leitura em geral e, relacionado à leitura de gêneros da esfera jornalística, afirmaram não ler, além de a maioria nunca ter visto um exemplar de jornal.

Apesar de os PCNs (BRASIL, 1998, p. 54) destacarem que "um leitor competente é alguém que compreende o que lê" e sugerirem leituras por meio de jornais, revistas, fotos de família, enfatizarem a importância de ler imagens, uma vez que estas, além de serem textos, compõem-se como unidade significativa. Sugerem, ainda, que o professor desenvolva práticas leitoras com textos de gêneros variados, mas priorize os que circulam socialmente, infelizmente, nas salas de aula, o livro didático tem sido basicamente o único material utilizado nas aulas de leitura.

Todavia, para que melhores resultados possam ser alcançados na formação de leitores proficientes, orienta-se planejamentos que oportunizem aos estudantes a leitura de textos diversificados, que possam contribuir para a formação do repertório do leitor quanto à diversidade de gêneros, dos recursos linguísticos, da organização textual. Haja vista que para levar os estudantes a ler com frequência e ajudá-los a gostar de ler, o professor precisa mostrar-lhes que a leitura pode ser prazerosa e, ao mesmo tempo, útil. Os aprendizados da leitura e da escrita iniciam-se na alfabetização e configuram-se, ou deveriam configurar-se como um processo constante e motivador. Nesse processo, é fundamental que as aulas oportunizem o acesso a materiais que tornem o exercício da leitura uma prática significativa.

Contudo, o desafio da escola contemporânea é oportunizar aos estudantes, práticas criativas de leitura e escrita, despertando-lhes a curiosidade e o gosto, porém o que acontece muitas vezes é que o ato de ler é imposto como uma atividade obrigatória, realizada em voz alta com fim apenas de cumprir uma atividade pedagógica. Diante desta realidade, Lerner 
(2002, p. 17) afirma que "para formar todos os alunos como praticantes da cultura escrita, é necessário conceitualizar o objeto de ensino e construí-lo tomando como referência fundamental as práticas sociais de leitura e escrita."

No segundo momento os estudantes foram direcionados ao laboratório de informática, onde assistiram ao vídeo intitulado "A evolução tecnológica do jornalismo no Brasil"”. Após a exibição do filme, retornaram à sala e receberam da professora exemplares impressos do jornal "A Gazeta de Cuiabá". O material foi conseguido por meio de doação, uma vez que no município não havia assinantes desse e de nenhum outro jornal impresso. Ressalta-se, porém, que a disponibilização de exemplares de jornais impressos aos estudantes é uma importante prerrogativa quando se trabalha com gêneros textuais da esfera jornalística, uma vez que:

Oferecer o jornal como um todo: cuidar para que os alunos tenham em mãos todo o jornal. Mesmo que "precisemos" apenas de uma parte dele para debater/estudar algum assunto em sala de aula, os alunos devem ter a oportunidade de saber de que parte aquela matéria jornalística foi retirada (editorial, caderno etc.) (LOZZA, 2009, p. 59).

Prosseguiu-se com a atividade distribuindo exemplares do jornal para todos os estudantes, orientou-se que observassem todo o material, folheassem, explorassem e lessem apenas aquilo que fosse do interesse de cada um, sem roteiro previamente estabelecido. Os estudantes se entusiasmaram e se surpreenderam com tantas cores e imagens, como também com a quantidade de textos, de diferentes gêneros, com funções sociais distintas, em um único suporte.

$\mathrm{Na}$ aula seguinte o trabalho foi retomado a partir da redistribuição dos exemplares do jornal e, dessa vez, conduziu-se a leitura, explorando os cadernos, orientando os estudantes a observar atenciosamente as imagens e a relação delas com o texto, explorando a capa do jornal e seu layout. A professora destacou a forma como os assuntos são abordados, levandose em conta o grau de relevância, intencionalidade, e demais aspectos típicos do jornal. A exploração desses aspectos possibilitou destacar algumas características dos gêneros, pois como afirma Alves Filho (2011, p. 31), “aprender gêneros pode ser uma forma de aprender a fazer escolhas responsáveis e deliberadas entre possibilidades existentes de combinação entre forma, conteúdo e valores expressos".

Na próxima aula os estudantes foram levados ao laboratório de informática, para uma visita ao site do Jornal A Gazeta Digital ${ }^{5}$. A página foi projetada no telão por meio do projetor

\footnotetext{
${ }^{4}$ Disponível em https://www.youtube.com/watch. Acesso em: 08 mar 2018.
}

${ }^{5}$ Disponível em: www.gazetadigital.com.br. Acesso em: 08 mar 2018. 
multimídia. Embora a orientação inicial fosse que cada grupo de no máximo três estudantes utilizassem um computador para visitar o site e explorar o jornal da maneira desejada, não foi possível porque o laboratório de informática possui apenas três computadores em funcionamento e na turma havia, neste dia, vinte e oito estudantes, ainda assim foi possível explorar o site e dialogar acerca das diferenças e semelhanças entre o jornal digital e jornal impresso.

A leitura e a navegação em sites, blogs e redes sociais diversas são algumas das possibilidades para trabalhos com textos no ambiente digital. Explorar suas potencialidades e usabilidade significa leva em conta não só a forma de organizar os discursos verbais, como os ícones, a estrutura da interface, o leiaute, dentre outros aspectos (COSCARELLI, 2016, p. 25).

No encontro seguinte retomou-se o trabalho com o conceito de gêneros textuais e, novamente, com os exemplares do jornal impresso em mãos, iniciaram-se as discussões acerca dos gêneros que comporiam o jornal escolar. A professora solicitou que sugerissem os gêneros que acreditavam ser relevantes para o trabalho da turma e justificassem sua escolha. O gênero notícia foi o primeiro a ser sugerido, essa escolha foi importante, pois “"...] a notícia é um dos gêneros aos quais as pessoas estão mais intensamente expostas [...]. [...] chegam até nós sem "pedir licença" e, [...] exibem-se para nós como que chamando para serem lidas" (ALVES FILHO, 2011, p. 90).

Posteriormente, a professora problematizou a importância de o estudante expor o que pensa a respeito do mundo que o cerca e das questões diárias da escola e da comunidade. Assim, por meio do diálogo e da argumentação da professora, os estudantes entenderem a importância dos textos de opinião, como a carta do leitor e o artigo de opinião fazerem parte de um jornal escolar.

Para finalizar essa etapa de escolhas de gêneros, abordou-se a importância de o jornal abrir espaço para a presença de pessoas da sociedade rioclarense que se destacam como cidadãos engajados em tornar a comunidade melhor, sejam em suas profissões ou ações sociais. Com isso, a entrevista jornalística foi escolhida como mais um gênero de relevância para o jornal escolar. O trabalho com esse gênero destacou-se tendo em vista que "a entrevista, nas suas diferentes aplicações, é uma técnica de interação social, de interpenetração informativa, quebrando assim isolamentos grupais, individuais, sociais; pode também servir à pluralização de vozes e à distribuição democrática da informação" (MEDINA, 1990, p. 08). 
Ao concluir a primeira fase do trabalho para a escolha dos gêneros textuais que comporiam o jornal escolar, observou-se que a realização desta etapa foi de suma importância para que os estudantes percebessem a relevância que cada gênero textual apresentado no contexto de produção de um jornal e compreendessem a contribuição que o acesso aos textos de diferentes gêneros pode trazer para o processo de aprendizagem dentro e fora da escola.

Após a escolha dos gêneros textuais pelos estudantes, a professora planejou as $4 \mathrm{SD}$ e desenvolveu-a na turma do $9^{\circ}$ ano, como se observa nos quadros $1,2,3$ e 4.

\section{Quadro 1 - SD 1-Notícia}

HORAS AULA: 08 horas aula

\section{SEQUÊNCIA DIDÁTICA 1 - NOTÍCIA}

OBJETIVOS: Apresentar o gênero textual notícia, seus aspectos estruturais, a linguagem utilizada e a relevância deste gênero para a sociedade de leitores. Bem como tratar questões de intencionalidade quando se produz uma notícia, a importância das imagens e da escolha do título para o texto.

\section{SITUACÃO INICIAL:}

$>$ Levantar questionamentos na sala sobre questões que poderiam se tornar notícias na escola em que estudam e como abordariam os temas apresentados (com muita ou pouca ênfase, dando destaque a que aspecto etc.).

$>$ Anotar os temas sugeridos no quadro;

$>$ Perguntar que tipo de jornal noticiaria aquele fato.

\section{PRODUCÃO INICIAL:}

$>$ Pedir que os estudantes, sentados em duplas, escolham um tema que está anotado no quadro e produzam, de maneira bem objetiva, uma notícia, dando destaque ao que eles quiserem.

$>$ Recolher os textos e realizar as correções, dando destaque as questões da escolha da linguagem, título do texto, objetividade das informações e demais questões de linguística.

\section{MÓDULO I:}

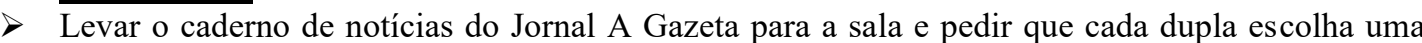
notícia e destaque dela o que é comum: título, estrutura do texto, informações etc.; e anotem no caderno.

$>$ Falar com a turma sobre os aspectos estruturais comuns a toda notícia e que não pode faltar quando se trata desse gênero textual: Onde? Como? Quando? Por quê? Quem?

$>$ Destacar a importância de um bom título, da lide que apresenta o assunto ao leitor e a da linha fina;

$>$ Enfatizar a linguagem utilizada pelo jornalista e o que ele pretende destacar em seu texto, intencionalidade.

\section{MÓDULO II:}

$>$ Apresentar a partir da utilização do projetor multimídia três imagens retiradas de notícias da internet e pedir que cada dupla escolha uma imagem e produza uma notícia, pautadas nas características já trabalhadas sobre o gênero notícia;

$>$ Proposta de produção de notícia para apresentação na sala na aula seguinte.

$>$ MÓDULO III:

$>$ Com o auxílio do projetor multimídia cada dupla apresentará sua notícia para a sala;

$>$ Depois de finalizadas as apresentações, a professora mostrará aos estudantes as três notícias originais que acompanhavam as imagens retiradas da internet;

$>$ Discutir sobre o poder das imagens e a quantidade de suposições que podemos ter em uma única imagem, dependendo de quem a observa, a importância do título do texto e da linha fina.

\section{PRODUTO FINAL:}

$>$ Entregar as notícias produzidas no início da SD e pedir que cada dupla observe os aspectos que estão falhos e refaçam seus textos agora seguindo o roteiro estrutural de uma notícia.

Fonte: Elaborado pelas autoras 


\section{Quadro 2 - SD 2 - Cartas do Leitor}

HORAS AULA: 06 horas/aula

OBJETIVOS: Mostrar aos estudantes que eles podem realizar ações sociais por meio de cartas do leitor, ao explicitar a sua opinião diante de fatos públicos e de interesse coletivo, podem elogiar, dar sugestões e mostrar que sua voz pode ser ouvida mesmo nos grandes veículos de comunicação, distantes da realidade em que vivem: como revistas, jornais, sites etc.

\section{SITUACÃO INICIAL:}

$>$ Iniciar um diálogo em sala com o intuito de explanar aos estudantes a importância das cartas do leitor para a interação entre o leitor e os veículos de comunicação de massa.

$>$ Levantar questionamentos de assuntos relacionados ao ambiente escolar que os estudantes gostariam de ter a oportunidade de opinar, questionar, criticar ou sugerir.

$>$ Organizar tópicos no quadro relacionado aos temas sugeridos pelos estudantes.

\section{PRODUÇÃO INICIAL:}

$>$ Organizar a sala em duplas de estudantes e sugerir que cada dupla escolha um tema e produza uma carta do leitor destinada a gestão da escola, para posterior exposição em um mural colocado no pátio, intitulado "Espaço do Aluno".

\section{MÓDULO I:}

$>$ Apresentar por meio do projetor multimídia as cartas produzidas pelos estudantes na aula anterior com o intuito de provocá-los quanto aos argumentos utilizados e a forma de defenderem o seu ponto de vista;

$>$ Apontar os argumentos falhos e a ausência de operadores argumentativos;

$>$ Destacar a falta de um título interessante e atrativo.

$>$ Apresentar lista de operadores argumentativos e falar sobre estrutura dos textos.

$>$ Propor atividade de refacção.

\section{MÓDULO II:}

$>$ Realizar a leitura de uma carta de leitor de uma revista conceituada, destacando para a sala sua intencionalidade ao produzir uma carta do leitor;

$>$ Interpretar e discutir o texto apresentado;

$>$ Criar um mural para a exposição dos textos no pátio da escola.

\section{MÓDULO III:}

$>$ Pesquisar temas na comunidade que poderiam se tornar cartas do leitor;

$>$ Analisar o foco argumentativo de cada tema e produzir uma carta direcionada ao órgão responsável pelo assunto em nossa cidade: secretaria de saúde, de educação, prefeitura etc.

\section{PRODUÇ̃̃O FINAL:}

$>$ Propor a produção de duas cartas do leitor: uma com foco em uma crítica e outra em um elogio a algo de interesse público e coletivo da cidade;

$>$ Digitar o texto e enviar no e-mail da professora madajusc@gmail.com;

$>$ Editar imagem que acompanha o texto.

Fonte: Elaborado pelas autoras

\section{Quadro 3 - SD 3 - Artigo de Opinião}

\section{HORAS AULA: 08 horas aula}

\section{SEQUÊNCIA DIDÁTICA 3 - Artigo de Opinião}

OBJETIVOS: Trabalhar com estudantes a capacidade de se posicionarem de maneira crítica e coerente frente aos assuntos que circulam na sociedade que requer do cidadão uma tomada de posição, bem como capacidades de estruturarem textos de opinião de maneira clara e objetiva, com argumentos bem fundamentados.

\section{SITUACC̃̃O INICIAL:}

$>$ Leitura em duplas do caderno Opinião do Jornal A Gazeta de Cuiabá;

$>$ Cada dupla escolherá um texto e lerá para a sala;

$>$ Destacar a forma com que os autores se posicionam frente a cada tema apresentado pelos estudantes no momento da leitura.

\section{PRODUÇÃO INICIAL:}

$>$ Proposta de produção de texto, tema: "O papel da internet na comunicação entre as pessoas".

$>$ Orientações: o texto deverá ter, no mínimo, três parágrafos e ser escrito em $3^{\mathrm{a}}$ pessoa.

RPGE- Revista on line de Política e Gestão Educacional, Araraquara, v. 25, n. 2, p. 1346-1363, maio/ago. 2021. e-ISSN: 1519-9029 


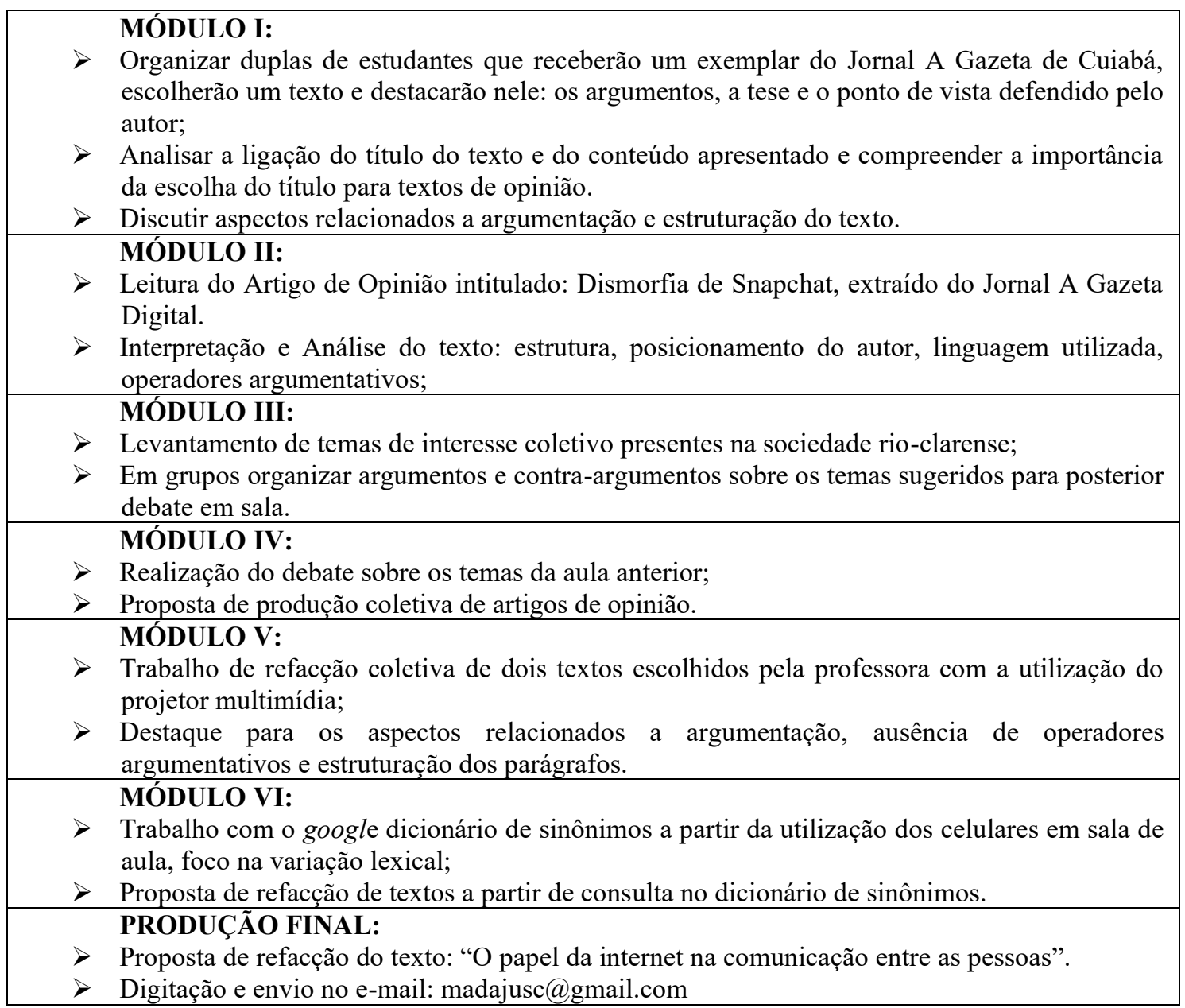

Fonte: Elaborado pelas autoras

\section{Quadro 4 - SD 4 - Entrevista Jornalística}

HORAS AULA: 08 horas aula

OBJETIVOS: Viabilizar a participação de pessoas influentes da comunidade nas edições do Jornal Digital. Conhecer as experiências pessoais e/ou profissionais de algumas personalidades rioclarenses bem como trabalhar com a linguagem oral, a interação dialógica e atividades de retextualização, importantes no processo de ensino aprendizagem de Língua Portuguesa.

\section{SITUACẼ̃O INICIAL:}

$>$ Dialogar com a turma sobre a importância das entrevistas jornalísticas nos meios de comunicação de massa;

$>$ Pedir sugestões de personalidade rio-clarenses que poderiam ser entrevistadas pela equipe do jornal da escola;

$>$ foco da entrevista com a pessoa sugerida. PRODUÇÃO INICIAL:

$>$ Escolher entre as sugestões de nomes uma pessoa para ser entrevistada pelo Jornal Digital;

$>$ Organizar duplas e propor que casa dupla produza duas perguntas a serem dirigidas ao entrevistado;

\section{MÓDULO I:}

$>$ Ler uma entrevista com o cartunista Laerte realizada pelo jornal Folha de São Paulo disponível no livro didático Projeto Teláris $-9^{\circ}$ ano, p. 166;

$>$ Interpretar a entrevista, discutir sobre o foco das perguntas, a linguagem utilizada e a situação comunicativa;

$>$ Trabalhar aspectos relacionados a retextualização das entrevistas MÓDULO II: 


\begin{tabular}{|c|c|}
\hline$>$ & $\begin{array}{l}\text { Organizados em grupos os estudantes escolheram uma personalidade rio-clarense para uma } \\
\text { suposta entrevista; } \\
\text { Elaboração de perguntas e destaque para o foco da entrevista: pessoal, profissional etc. }\end{array}$ \\
\hline$\vec{D}$ & $\begin{array}{l}\text { MÓDULO III: } \\
\text { Entrevista surpresa com o professor Edson Douglas da Silva; } \\
\text { Trabalho com gravacão de áudio, vídeo. }\end{array}$ \\
\hline$>$ & $\begin{array}{l}\text { MÓDULO IV: } \\
\text { Retextualização coletiva das respostas do professor, por meio da utilização de projetor } \\
\text { multimídia; } \\
\text { Digitação e edição das imagens para a organização da entrevista que seria publicada na } \\
\text { primeira edição do jornal digital da escola. }\end{array}$ \\
\hline$\vec{D}$ & $\begin{array}{l}\text { MÓDULO V: } \\
\text { Realização das entrevistas produzidas na sala pelos grupos de estudantes; } \\
\text { Atividades de retextualização em horário extraclasse; }\end{array}$ \\
\hline$\vec{D}$ & $\begin{array}{l}\text { PRODUÇÃO FINAL: } \\
\text { Digitação e edição de imagens para organização das entrevistas de cada grupo. } \\
\text { Envio das entrevistas prontas para o e-mail da professora: madajusc@gmail.com }\end{array}$ \\
\hline
\end{tabular}

Fonte: Elaborado pelas autoras

\section{Considerações finais}

Os resultados alcançados trouxeram contribuições teórico-metodológicas que poderão auxiliar outros profissionais que tiverem interesse em utilizar os gêneros textuais da esfera jornalística como instrumento pedagógico, uma vez que se observou ao longo das atividades trabalhadas, que os estudantes se empenharam e promoveram em sala de aula discussões acerca de assuntos reais e presentes, não só no ambiente escolar, mas também em sua comunidade, e, com isso, demonstraram criticidade e reflexibilidade frente as diferentes abordagens propiciadas por cada assunto discutidos.

Os resultados do desdobramento dessa pesquisa-ação, reeditou que os gêneros textuais da esfera jornalística muito contribuem para se trabalhar os conteúdos da língua portuguesa, com vistas a implementação de proposições pedagógicas centradas em uma perspectiva dialógica, democrática e crítica. Ou seja, o jornal pode e deve ser explorado em sala de aula com vistas a atualidade e autenticidade curricular. Como afirma Cortella apud Silva (2007, p. 20), "O Jornal é uma ferramenta que possui o poder imenso em ser ele a fazer o convite para as pessoas navegarem pelo presente e assim poderem caminhar no processo histórico passado e viajarem também em direção ao desejo e, portanto, ao futuro.”

Ressalta-se que todas as etapas realizadas foram necessárias para a elaboração do produto final. Além disso, estas etapas contribuíram para despertar nos estudantes o interesse pela leitura, bem como pela pesquisa de assuntos atuais que poderiam fazer parte do jornal. Ao entrevistar pessoas, buscar informações, investigar fatos e trazer para a sala de aula possibilidades de produções textuais que atendessem algumas necessidades dos possíveis 
leitores, o processo de aprendizagem ganhou vida e sentido, condições fundamentais para o envolvimento dos estudantes.

A realização das atividades trouxe informação, reflexão e entretenimento aos estudantes e comunidade escolar. Assim, reafirmou os pressupostos teóricos defendidos por Kleiman (1999, p. 383) de que "Os projetos de letramento requerem um movimento pedagógico que vai da prática social para o 'conteúdo' (seja ele uma informação sobre um tema, uma regra, uma estratégia ou procedimento), nunca o contrário”.

O processo de produção do jornal digital ajudou não só no desempenho e melhoria das competências em leitura e escrita dos estudantes, como sensibilizou e despertou neles o senso crítico, pois as atividades realizadas de coletas de informações, de produções textuais de diferentes gêneros, de apresentação gráfica das matérias, da edição das imagens, digitação e envio dos textos oportunizou a utilização de conceitos teóricos aprendidos em sala de aula. Essas atividades trouxeram para a escola práticas que os estudantes realizam fora dela enquanto adolescentes que estão sempre conectados à internet, possuem o hábito de lidar com as tecnologias, e usá-las em suas atividades escolares, por isso foi prazeroso e significativo para eles. Assim, as práticas multiletradas possibilitaram o protagonismo e o desenvolvimento de atitudes críticas frente ao contexto social.

Desse modo, as atividades realizadas promoveram o laboratório de informática como parte do processo de ensino aprendizagem da língua. Para Coscarelli (2012, p. 21) este espaço exige tanto a apropriação das tecnologias, "[...] quanto o desenvolvimento das habilidades para produzir associações e compreensões nos espaços multimidiáticos”, e essa foi uma das características das ações pedagógicas realizadas.

O interesse pela leitura e escrita aumentou gradativamente no decorrer da realização de todas as etapas desta pesquisa ação/intervenção, a partir do momento em que os estudantes entenderam que todos os textos que comporiam o jornal partiriam de temas extraídos do cotidiano deles e que as matérias retratariam a realidade da escola e da comunidade. A esse respeito argumenta-se que:

Se desejamos que nossos alunos queiram prestar atenção aos textos e queiram fazer sentidos deles, precisamos despertar o seu interesse pelos textos. Somente depois de termos evocado neles, os mecanismos de fazersentido, é que serão capazes de trabalhar as habilidades e técnicas que darão precisão e profundidade a suas leituras (BAZERMAN, 2006, p. 46).

Todavia, no decorrer do desdobramento das ações planejadas, registrou-se algumas dificuldades, como, por exemplo, o número de máquinas disponíveis no laboratório de 
informática da escola, além de não serem suficientes para todos os estudantes estavam ultrapassadas, o que dificultou a utilização. Além disso, nesta escola, o acesso à internet não estava liberado em todas as máquinas. Este problema foi parcialmente superado com a utilização de aparelhos celulares e de notebooks dos próprios estudantes que realizaram as atividades on-line em horários extraclasse e as enviaram para a professora para correções e apontamentos. Desta forma, muitas atividades foram realizadas. Estas atividades, provocaram interação e envolvimento da equipe que, com muito esforço, interesse e dedicação se empenharam para que os objetivos propostos em cada SD trabalhada fossem alcançados.

É importante deixar claro que as tecnologias por si só, não resolverão os problemas de aprendizagem da Língua Portuguesa. Contudo, estes recursos, associados e articulados com intervenções bem planejadas, poderão despertar maior interesse dos estudantes em leitura e escrita. Os conteúdos quando trabalhados de forma contextualizada e articulada aos fatos atuais e reais, certamente darão vida e sentido aos temas estudados nas aulas e resultarão na melhor aprendizagem dos estudantes.

Para tanto, faz-se necessário que o docente cumpra com sua função social não só de trabalhar conhecimento em sala de aula, mas de ser um agente de letramento, levando-se em conta o perfil dos estudantes envolvidos no processo e o que pode ser significativo para atingir determinados objetivos naquele contexto específico, mesmo porque:

[...] os letramentos são práticas sociais e culturais que têm sentidos específicos e finalidades específicas dentro de um grupo social, ajudam a manter a coesão e a identidade do grupo, são aprendidas em eventos coletivos de uso da leitura e da escrita, e por isso são diferentes em diferentes contextos socioculturais (BUZATO, 2016, p. 5)

No que se refere ao desenvolvimento das ações planejadas, analisou-se que num trabalho que objetive levar o estudante a ser protagonista no processo de aprendizagem, é fundamental que ele participe de todas as etapas, principalmente na elaboração do planejamento. O fato de o planejamento das ações, que culminou na publicização de um jornal escolar digital, ter sido desenvolvido de forma colaborativa, foi o primeiro passo que envolveu os estudantes a se responsabilizarem com o resultado deste trabalho.

É importante reiterar o fato de que, nas atividades escolares de modo geral, especificamente na questão do trabalho com leitura e produção de textos, é necessário que se leve em consideração o envolvimento do estudante no processo e não a sua participação como um mero coadjuvante, que apenas contempla algo que não pode e não deve interferir. Tal observação justifica-se por que a participação ativa possibilita tomadas de decisões, diante das 
ações, bem como de compromissos assumidos junto à turma e ao professor com os resultados alcançados ao final do trabalho.

Outro aspecto que merece destaque se refere às aulas que aconteceram fora do espaço escolar. Com estas aulas os estudantes realização entrevistas junto aos moradores da comunidade e pesquisaram fatos atuais para comporem o primeiro exemplar do jornal publicado na página da escola. A inclusão dessas atividades permitiu aos estudantes pensarem os usos da língua para além dos muros escolares e oportunizou reflexões acerca da necessidade de se ter uma visão crítica e conhecimento de mundo para que se possa ser protagonista de suas ideias.

Para finalizar estas reflexões destaca-se a importância de propiciar momentos de interação e afetividade junto aos estudantes, haja vista que essa aproximação permite que as atividades planejadas resultem na aprendizagem de língua portuguesa ou de qualquer outra disciplina. Visto que um ambiente de aprendizagem pautado em parceria, atenção e valorização pessoal pode gerar ganhos significativos e permitir que o projeto inicial do docente seja adotado por todos os envolvidos não por imposição do professor, mas pelo compromisso assumido por todos.

Neste sentido, apreende-se que as intervenções docentes, pautadas na perspectiva teórica dos multiletramentos, planejadas por meio de projeto de letramento e SD trazem dinamicidade ao processo de escolarização formal, pois viabiliza o envolvimento e a participação efetiva dos estudantes. Estas demandam iniciativa e boa vontade do professor que precisa contar também com o apoio da comunidade escolar e equipe gestora. $\mathrm{O}$ primeiro passo é envolver os estudantes, pois com o apoio deles, os obstáculos que surgirem serão mais fáceis de serem superados.

AGRADECIMENTOS: Coordenadoria de Aperfeiçoamento de Pessoal de Nível Superior (CAPES).

\section{REFERÊNCIAS}

ALVES FILHO, F. Gêneros Jornalísticos: notícias e cartas do leitor no ensino fundamental. São Paulo, SP: Cortez, 2011.

BAKHTIN, M. Estética da criação verbal. 4. ed. São Paulo, SP: Martins Fontes, 2003.

BAZERMAN, C. Gênero, agência e escrita. São Paulo, SP: Cortez, 2006. 
BORTONI-RICARDO, S. M. O professor pesquisador: introdução à pesquisa qualitativa. São Paulo, SP: Parábola Editorial, 2008.

BRASIL. Lei n. 9.394, de 20 de dezembro de 1996. Estabelece as Diretrizes e Bases da Educação Nacional. Brasília, DF, 1996. Disponível em: http://www.planalto.gov.br/ccivi 1_03/leis/19394.htm. Acesso em: 20 ago. 2018.

BRASIL. Parâmetros Curriculares Nacionais: língua portuguesa: $1^{\circ}$ e $2^{\circ}$ ciclos. Brasília, DF: SEF, 1998.

BUZATO, M. K. Letramentos Digitais e Formação de Professores. Campinas, SP: IEL UNICAMP, 2016. Disponível em: https://www.researchgate.net/publication/24222 9367_Letramentos_Digitais_e_Formacao_de_Professores. Acesso em: 10 ago. 2018.

CAVALCANTI, J. O Jornal como proposta pedagógica. São Paulo, SP: Paulus, 1999.

COSCARELLI, C. V. Tecnologias para aprender. 1. ed. São Paulo, SP: Parábola Editorial, 2016.

COSCARELLI, C. V.; RIBEIRO, A. E. (Org.) Letramento digital: aspectos sociais e possibilidades pedagógicas. 2. ed. Belo Horizonte, MG: Ceale: Autêntica, 2012.

FREIRE, P. Pedagogia da autonomia: saberes necessários à prática educativa. São Paulo, SP: Paz e Terra, 1996.

KLEIMAN, A. C. B. R.; MATÊNCIO, M. L. M. (Org.). Letramento e formação do professor: práticas discursivas, representações e construção do saber. Campinas, SP: Mercado de Letras, 2005. (Coleção Ideias sobre Linguagem)

KLEIMAN, A. C. B. R.; MORAES, S. E. Leitura e interdisciplinaridade: tecendo redes nos projetos da escola. Campinas, SP: Mercado de Letras, 1999.

LERNER, D. Ler e escrever na escola: o real, o possível e o necessário. Trad. Ernani Rosa. Porto alegre, RS: Artmed, 2002.

LOZZA, C. Escritos sobre o jornal: olhares de longe e de perto. Apresentação de Emir Sader. São Paulo, SP: Global, 2009.

MARCUSCHI, L. A. Da fala para a escrita: atividades de retextualização. 6. ed. São Paulo, SP: Cortez, 2005.

MARCUSCHI, L. A. Produção textual, análise de gêneros e compreensão. São Paulo, SP: Parábola, 2008.

MEDINA, C. A. Entrevista: o diálogo possível. 3. ed. São Paulo, SP: Ed Ática, 1990.

ROJO, R. H. R. Letramentos Múltiplos, escola e inclusão social. 1. ed. São Paulo, SP: Parábola Editorial, 2009.

ROJO, R. H. R. Multiletramentos na escola. São Paulo, SP: Parábola Editorial, 2012.

RPGE- Revista on line de Política e Gestão Educacional, Araraquara, v. 25, n. 2, p. 1346-1363, maio/ago. 2021. e-ISSN: 1519-9029 
SCHNEUWLY, B.; DOLZ, J. Gêneros orais e escritos na escola. Campinas, SP: Mercado de Letras, 2004.

SILVA, E. T. (Org.). O jornal na vida do professor e no trabalho docente. Campinas, SP: Global, 2007.

SILVA, E. T. O Jornal na vida do professor e no trabalho docente. São Paulo, SP: Global, 2007.

THIOLLENT, M. Metodologia da pesquisa-ação. São Paulo, SP: Cortez, 2008.

ZABALZA, M. Diários de aula: um instrumento de pesquisa e desenvolvimento profissional. Porto Alegre, RS: Artmed, 2004.

\section{Como referenciar este artigo}

PARREÃO, M. R. C.; MELLO, Â R. C. Gêneros textuais, multiletramento e produção de jornal digital. Revista on line de Política e Gestão Educacional, Araraquara, v. 25, n. 2, p. 1346-1363, maio/ago. 2021.

https://doi.org/10.22633/rpge.v25i2.14793

Submetido em: $22 / 02 / 2021$

Revisões requeridas em: 08/04/2021

Aprovado em: $23 / 04 / 2021$

Publicado em: 01/08/2021 